\title{
A Study on Bacterial Isolates and Their Antibacterial Susceptibility Pattern in Patients with Spontaneous Bacterial Peritonitis in a Tertiary Care Hospital
}

\author{
C. Nithya ${ }^{1 *}$, N. Rathnapriya ${ }^{2}$ and S. Vasanthi \\ ${ }^{1}$ Department of Microbiology, Institute of Children, Madras Medical College, \\ Egmore, Chennai, Tamil Nadu, India \\ ${ }^{2}$ Department of Microbiology, Madras Medical College \& RGGGH, Chennai, Tamil Nadu, India \\ *Corresponding author
}

Keywords

Spontaneous bacterial peritonitis (SBP), Ascitic fluid, Ascitic fluid culture, Gram stain.

Article Info

Accepted:

10 July 2017

Available Online:

10 September 2017

\section{A B S T R A C T}

Primary peritonitis is otherwise known as Spontaneous Bacterial Peritonitis ((SBP) which is defined as the infection of ascitic fluid without any primary source of infection such as intra-abdominal pathology or perforation of intestine or viscus in the peritoneal cavity. SBP is due to spread of infection from Tran's mural migration of intestinal organisms into the peritoneal cavity. Spontaneous Bacterial Peritonitis most commonly occurs in cirrhotic patients with ascites due to their poor immune response in ascitic fluid and decreased intestinal motility. The present study was conducted during a one year period (Jan 2013 to Dec 2013). A total of 100 patients with Cirrhotic liver and ascites were included in this study. Gram stain and culture were performed. Antibiotic susceptibility testing was performed by Kirby Bauer disc diffusion method on Mueller Hinton agar. Out of 100 patients, 36 patients were diagnosed as having SBP. There were 24 males and 12 females. In this study, Escherichia coli (54\%) was the most common isolated organism followed by Klebsiella pneumoniae (15\%). Among the Gram Positive Cocci (GPC), Streptococcus viridans (11\%) was the most common isolate followed by Staphylococcus aureus (7\%).All isolated GNB were $100 \%$ sensitive to Imipenem and among the GPC, all were sensitive to Vancomycin. Appropriate use of selective intestinal decontamination with antibiotics in patients with ascites and also strict follow up of empirical therapy will prevent the severity of SBP.

\section{Introduction}

Peritonitis is an inflammatory condition of the peritoneum. It is caused by a bacterial or fungal infection. Bacterial peritonitis is more common than fungal peritonitis. Primary and secondary peritonitis are the two major types of peritonitis. Both cases of peritonitis are very serious and can be life threatening if not treated immediately. Primary peritonitis is otherwise known as Spontaneous Bacterial Peritonitis (SBP) which is defined as the infection of ascitic fluid without any primary source of infection such as intra-abdominal pathology or perforation of intestine or viscus in the peritoneal cavity. SBP is due to spread of infection from transmural migration of intestinal organisms into the peritoneal cavity. Spontaneous Bacterial Peritonitis most commonly occurs in cirrhotic patients with ascites due to their poor immune response in ascitic fluid and decreased intestinal motility. The bacteria that are responsible for the peritonitis are derived from the normal flora 
of the gastrointestinal tract [GIT] 1. Majority of SBP is due to Gram negative organisms in the intestine. So, the knowledge of the types of the normal microbial flora which are present in the GIT is important to understand the spectrum of peritonitis.

The prevalence of peritonitis in patients with ascites is as high as $18 \%$ [2]. Due to the increased awareness of SBP, diagnostic rate has increased from $8 \%$ to $18 \%$ over the past two decades [4]. Primary peritonitis develops in up to $25 \%$ of patients with alcoholic cirrhosis 5.The mortality rate due to SBP in hospitalized patients who are admitted for recurrent SBP may range from 50\% to $70 \%$ [6]. But the mortality rate may be low $(5 \%)$ in patients who arediagnosed early and treated immediately. So, the treatment of peritonitis depends upon, better understanding of the pathophysiology of peritonitis, bacterial flora of the peritoneal cavity, systemic inflammatory response due to intraperitoneal infections, the development of scoring systems and their application to patients with peritonitis.

Therefore, an attempt is madeto isolate the microorganisms responsible for causing the infection in asciticfluid of Cirrhotic patients and their antimicrobial susceptibility pattern.

\section{Materials and Methods}

The present study was during a one year period (Jan 2013 to Dec 2013). Approval was obtained from the Institutional Ethical Committee before commencement of the study. Informed consent was obtained from the study population. A total of 100 patients with Cirrhoticliver andasciteswere included in thisstudy. Patients with ascites due to renal, cardiac, tubercular, malignant pathology and secondary peritonitis were excluded from this study.Patients were interviewed by a structured questionnaire.

\section{Sample collection, Transport and processing}

Under strict aseptic precautions, ascetic fluid samples were collected from the patientsand transported to the laboratory immediately in appropriate settings asdescribed below and sample processing performed as per standard operatingprocedures.15-20 $\mathrm{ml}$ of freeascitic fluid in the abdomen was aspirated by paracentesis [abdominal tapping] under strict aseptic precautions with ultrasound guidance and inoculated in to $50 \mathrm{ml}$ of Brain heart infusion broth at the bedside [7].

\section{Processing of samples}

\section{Direct smear examination $^{[7]}$}

$5-10 \mathrm{ml}$ of aspirated ascetic fluid observed for macroscopiccharacteristic features of fluid (colour, turbidity, purulent, blood stained). Then ascitic fluid was centrifuged at $1500 \mathrm{rpm}$ for $10 \mathrm{mins}$ and thesupernatant was discarded and the sedimentdivided in to 3 parts [8]. The sediment was processed by the followingmethods. 1st part of sediment was used for smear preparation for Gramstaining, AFB staining. Gram stained smears observed for the presence orabsence of Poly Morpho Nuclear leukocytes (PMNs) and bacteria.[8].The second part of sediment was used for AFB staining.

\section{Culture $^{[8]}$}

The third part of sediment was plated on to the following media, 5\% sheep blood agar,Chocolate agar, MacConkey agar. All inoculated plates were incubated at aerobic condition and in a carbondioxide enrichedatmosphere by using candle jar. Plates were examined for growth at 24 and 48hours and discarded after 5 days. 


\section{Data collection}

Data collection included name, age, address, date of admission, diagnosisat admission, habitual history[smoking, alcoholism], Medical history, physicalexamination findings, nutritional status were also included.

\section{Interpretation of bacterial cultures ${ }^{[10]}$}

Bacterial isolates were identified by means of colony morphology, Gramstaining, motility and biochemical reactions by standard microbiologicaltechniques as recommended by Clinical and Laboratory StandardsInstitute (CLSI).

\section{Antimicrobial sensitivity testing}

Antibiotic susceptibility testing was performed by the Kirby Bauermethod on Mueller Hinton agar (Himedia) according to CLSI guidelines [9].The diameters of zones of inhibition were interpreted according to CLSIstandards for each organism. Media and discs were tested for quality controlusing standard strains.

The following standard strains were used,

Staphylococcus aureus- ATCC 25923

Escherichia coli-ATCC 25922

Pseudomonas aeruginosa-ATCC 27853

\section{Results and Discussion}

Total number of 100 patients with Spontaneous Bacterial peritonitis who satisfied the inclusion criteria were included in this study from Jan 2013 to Dec 2013.

Out of 100 patients, 36 patients were diagnosed as having SBP. There were 24 males and 12 females. This high male gender predominance due to the increased risk of alcohol consumption, smoking habits, which were commonly prevalent among them. $(5,6)$ have reported similar male predominance in SBP.

In this study, out of the 100 patients with SBP, 21(58.33\%) patients were in the age group of 41- 60 years (Table 1).

Hoefs 2002 et al., 7 has reported the similar age group 41-60 years distribution in SBP and explained that older patients had low complement level and also had low phagocytic activity in ascitic fluid, which leads to increased survival of migrated enteric organisms from intestine. Also, majority of patients with SPB were cirrhotic patients with low complement level in ascitic fluid.

In this study, majority of isolated organisms were aerobic Gram Negative Bacilli(GNB), mainly enteric Gram negative organisms and among them, Escherichia coli (54\%) was the most common isolate followed by Klebsiella pneumoniae (15\%), Pseudomonas aeruginosa (5\%). Among the Gram Positive Cocci (GPC) Streptococcus viridans (11\%) was the most common isolate followed by Staphylococcus aureus $(7 \%)$ and Enterococcus feacalis (3\%) (Table 3). This correlates with Rim land et al., 2007 et al., 6, Weinstein 2000 et al., 8 and Hoefs 2002 et al., 7.

In this present study, most of the isolated GNB were resistant to third generation cephalosporins and ciprofloxacin. Among the GNB, 50\% of Escherichia coli and Klebsiella pneumoniae were resistant to third generation cephalosporins and ciprofloxacin (Table 3). All GNB were showed $100 \%$ sensitivity for imipenem. Alexopoulou A 2013 et al., 9has reported similar third generation cephalosporin and quinolone resistance was observed in $49 \%$ and $47 \%$ of GNB isolates respectively. In contrast, Mirnejad 2011 et al., 10has reported majority of patients $(85 \%)$ were sensitive to third generation 
cephalosporins and fluoroquinolones.

In this present study, among the isolated Staphylococcus aureus, 3 were methicillin sensitive and one [50\%] isolate was resistant to methicillin but found to be sensitive to vancomycin and all were showed $100 \%$ sensitivity for amikacin and vancomycin.

Majority of isolates responsible for SBP were enteric Gram negative organisms and Escherichia coli (54\%) was the most common isolated organism followed by Klebsiella pneumoniae (15\%). Among the Gram Positive Cocci (GPC), Streptococcus viridans $(11 \%)$ was the most common isolate followed by Staphylococcus aureus (7\%).All isolated GNB were $100 \%$ sensitive to Imipenem and among the GPC, all were sensitive to Vancomycin. Appropriate use of selective intestinal decontamination with antibioticsin patients with ascites and also strict follow up of empirical therapy will prevent the severity of SBP.

Table.1 Sex distribution of SPB patients

\begin{tabular}{|l|l|l|l|l|l|l|l|}
\hline S.No & Age Group & Male & \% & Female & \% & Total & \% \\
\hline 1 & $21-40$ & 5 & 14 & 4 & 11 & 9 & 25 \\
\hline 2 & $41-60$ & 15 & 42 & 6 & 17 & 21 & 58 \\
\hline 3 & $>60$ & 4 & 11 & 2 & 5 & 6 & 17 \\
\hline Total & $\mathbf{2 4}$ & $\mathbf{6 7}$ & $\mathbf{1 2}$ & $\mathbf{3 3}$ & $\mathbf{3 6}$ & $\mathbf{1 0 0}$ \\
\hline
\end{tabular}

Table.2 Organism isolated

\begin{tabular}{|l|l|l|l|}
\hline S.No & Organism & No & $\mathbf{\%}$ \\
\hline $\mathbf{1}$ & Escherichia coli & $\mathbf{1 8}$ & $\mathbf{5 4}$ \\
\hline $\mathbf{2}$ & Klebsiella pneumoniae & $\mathbf{6}$ & $\mathbf{1 5}$ \\
\hline $\mathbf{3}$ & Proteus mirabilis & $\mathbf{2}$ & $\mathbf{5}$ \\
\hline $\mathbf{4}$ & Pseudomonas aeruginosa & $\mathbf{2}$ & $\mathbf{5}$ \\
\hline $\mathbf{5}$ & Streptococcus viridans & $\mathbf{4}$ & $\mathbf{1 1}$ \\
\hline $\mathbf{6}$ & Staphylococcus aureus & $\mathbf{3}$ & $\mathbf{7}$ \\
\hline $\mathbf{7}$ & Enterococcus feacalis & $\mathbf{1}$ & $\mathbf{3}$ \\
\hline & Total & $\mathbf{3 6}$ & $\mathbf{1 0 0}$ \\
\hline
\end{tabular}


Table.3 Antibiotic sensitivity pattern of isolated organisms in SPB

\begin{tabular}{|c|c|c|c|c|c|c|c|c|c|c|c|c|c|}
\hline Organism[n] & AK & GM & CEF & CEZ & OF & $\mathrm{CO}$ & $\mathrm{CF}$ & $\mathbf{P}$ & $\begin{array}{l}\text { CT } \\
\mathbf{N}\end{array}$ & $\mathbf{C P}$ & IMP & PT & $\mathbf{V A N}$ \\
\hline $\begin{array}{l}\text { Escherichia coli } \\
\text { [18] }\end{array}$ & $\begin{array}{l}10 \\
{[55 \%]}\end{array}$ & $\begin{array}{l}6 \\
{[33 \%]}\end{array}$ & $\begin{array}{l}9 \\
{[50 \%]}\end{array}$ & $\begin{array}{l}9 \\
{[50 \%]}\end{array}$ & $\begin{array}{l}8 \\
{[44 \%]}\end{array}$ & $\begin{array}{l}4 \\
{[22 \%]}\end{array}$ & $\begin{array}{l}9 \\
{[50 \%]}\end{array}$ & - & - & - & $\begin{array}{l}18 \\
{[100 \%]}\end{array}$ & $\begin{array}{l}18 \\
{[100 \%]}\end{array}$ & - \\
\hline $\begin{array}{l}\text { Klebsiella } \\
\text { pnemoniae [6] }\end{array}$ & $\begin{array}{l}3 \\
{[50 \%]}\end{array}$ & $\begin{array}{l}2 \\
{[33 \%]}\end{array}$ & $\begin{array}{l}3 \\
{[50 \%]}\end{array}$ & $\begin{array}{l}3 \\
{[50 \%]}\end{array}$ & $3[50 \%]$ & $2[33 \%]$ & $3[50 \%]$ & - & - & - & $6[100 \%]$ & $\begin{array}{l}6 \\
{[100 \%]}\end{array}$ & - \\
\hline $\begin{array}{l}\text { Proteus } \\
\text { mirabilis [2] }\end{array}$ & $\begin{array}{l}2 \\
{[100 \%]}\end{array}$ & $\begin{array}{l}2 \\
{[100 \%]}\end{array}$ & $\begin{array}{l}2 \\
{[100 \%]}\end{array}$ & $\begin{array}{l}2 \\
{[100 \%]}\end{array}$ & $\begin{array}{l}2 \\
{[100 \%]}\end{array}$ & $\begin{array}{l}2 \\
{[100 \%]}\end{array}$ & $\begin{array}{l}2 \\
{[100 \%]}\end{array}$ & - & - & - & $\begin{array}{l}2 \\
{[100 \%]}\end{array}$ & $\begin{array}{l}2 \\
{[100 \%]}\end{array}$ & - \\
\hline $\begin{array}{l}\text { Pseudomonas } \\
\text { aeruginosa[2] }\end{array}$ & $\begin{array}{l}1 \\
{[50 \%]}\end{array}$ & 0 & $\begin{array}{l}1 \\
{[50 \%]}\end{array}$ & $\begin{array}{l}2 \\
{[100]}\end{array}$ & $\begin{array}{l}2 \\
{[100 \%]}\end{array}$ & $\begin{array}{l}1 \\
{[50 \%]}\end{array}$ & $2[100 \%]$ & - & - & - & $2[100 \%]$ & $\begin{array}{l}2 \\
{[100 \%]}\end{array}$ & - \\
\hline $\begin{array}{l}\text { Streptococcus } \\
\text { viridans [4] }\end{array}$ & $\begin{array}{l}4 \\
{[100 \%]}\end{array}$ & - & - & - & $\begin{array}{l}4 \\
{[100 \%]}\end{array}$ & $\begin{array}{l}2 \\
{[50 \%]}\end{array}$ & $3[75 \%]$ & $\begin{array}{l}2 \\
{[50 \%]}\end{array}$ & - & $\begin{array}{l}3 \\
{[75 \%]} \\
\end{array}$ & - & - & $4[100 \%]$ \\
\hline $\begin{array}{l}\text { Staphylococcus } \\
\text { aureus [3] }\end{array}$ & $\begin{array}{l}3 \\
{[100 \%]}\end{array}$ & - & - & - & $2[66 \%]$ & $1[33 \%]$ & $2[66 \%]$ & $1[33 \%]$ & $\begin{array}{l}2[66 \\
\%]\end{array}$ & $\begin{array}{l}2 \\
{[66 \%]}\end{array}$ & - & - & $3[100 \%]$ \\
\hline $\begin{array}{l}\text { Enterococcus } \\
\text { feacalis }[4]\end{array}$ & $\begin{array}{l}3 \\
{[75 \%]}\end{array}$ & - & - & - & $3[75 \%]$ & 0 & $3[75 \%]$ & 0 & - & $\begin{array}{l}1 \\
{[25 \%]}\end{array}$ & - & $\begin{array}{l}4 \\
{[100 \%]}\end{array}$ & $4[100 \%]$ \\
\hline
\end{tabular}

AK-Amikacin,GM-Gentamycin,CEF-Cefotaxime,CEZ-Ceftazidime,OF-Ofloxacin,CO-Cotrimoxazole,CF-ciprofloxacin,P-

Penicilin,CTN-Cefoxitin,ERY-Erythromycin,CP-Cephalexin,IMP-Imipenam,PT-Piperacillin --Tazobactum, VAN-Vancomycin. 


\section{References}

1.Bailey \&Scott's and text book of Diagnostic Microbiology. Eleventh Edition, 2009: 904-907.

2.Evens LT, Kim WR, PoteruchaJJ, Kamath PS. Spontaneous bacterial peritonitis in asymptomatic outpatients with cirrhotic ascites. Hepatology.Apr 2003; 37(4); 897-901.

3.Ajitpal Singh Gill, Amandeep Singh, Prithpal Singh Matreja, Rajoo Singh Chinna Rajesh Mahajan, Deepinder Kaur Chhina. Spontaneous Bacterial Peritonitis in Alcoholic Cirrhosis: An Indian Perspective. Hepatology; 2007; 38(3): 846-852.

4.Alaniz C, Regal RE (April 2009). Spontaneous Bacterial Peritonitis: A Review of Treatment Options. P T 34 (4): 204-210.

5.Spontaneous bacterial peritonitis analysis of treatment and outcome Can J infectious disease 2001.147-154?

6.Rimland D, Hand WH. Spontaneous peritonitis: A reappraisal. Am J MedSci.2007; 293:285-92.

7.HoefsJC, Canawati HN, Sapico FL, Hopkins RR, Weiner J, Montgomerie JZ. Spontaneous bacterial peritonitis. Hepatology. 2002; 2:399-407.
8.Weinstein MP, Iannini PB, Stratton CW, Eickoff TC. Spontaneous bacterial peritonitis: A review of 28 cases with emphasis on improved survival and factors influencing prognosis. Am J Med. 2000; 64:592-8?

9.Alexopoulou A, Papadopoulos N, Eliopoulos DG, Alexaki A, Tsiriga A, Toutouza. M, Pectasides D. Increasing frequency of gram-positive cocci and gram-negative multidrug-resistant bacteria in spontaneous bacterial peritonitis Liver Int. 2013 Aug; 33(7): 975-81. doi: 10.1111/liv.12152. Epub 2013 Mar 24.

10.Mirnejad R, Jeddi F, Kiani J, Khoobdel M Etiology of spontaneous bacterial peritonitis and determination of their antibiotic susceptibility patterns in Iran. Asian Pacific $\mathbf{J}$ of Tropical medicine (2011) Pp. 116-118.

11.Dupeyron C, Campillo SB, Mangeney N, Richardet JP, Leluan G. Carriage of Staphylococcus aureus and of gramnegative bacilli resistant to thirdgeneration cephalosporins in cirrhotic patients: a prospective assessment of hospital-acquired infections.. Infect Control Hosp Epidemiol. 2001 22(7): 427-232.

\section{How to cite this article:}

Nithya, C., Rathnapriya, N. and Vasanthi, S. 2017. A Study on Bacterial Isolates and Their Antibacterial Susceptibility Pattern in Patients with Spontaneous Bacterial Peritonitis in a Tertiary Care Hospital. Int.J.Curr.Microbiol.App.Sci. 6(9): 3704-3709. doi: https://doi.org/10.20546/ijcmas.2017.609.457 